\title{
How did luxury brands do to overcome the COVID-19
}

\author{
Qinglong $\mathrm{Ma}^{1{ }^{1 *}}$ \\ ${ }^{1}$ Bishop Ready High School, Columbus, Ohio, 43220, USA \\ * Correspondence: derickma105@gmail.com
}

(Received: 12/28/2020; Accepted: 01/11/2021; Published: 01/13/2021)

DOI: https://doi.org/10.37906/isteamc.2021.1

\begin{abstract}
There is an unprecedented global outbreak of plague. By December 2020, there have been more than 78 million cases in the world, and more than 17 million patients died. The epidemic not only causes huge casualties in the world, but also has a huge impact on the economic world, especially for the luxury industry since the interests of the luxury industry largely depend on physical stores, offline services and other physical profit-making methods. The social isolation caused by the epidemic will greatly affect the income of offline services. This paper will make a detailed analysis of how the luxury industry spent the epidemic from three aspects: raising the price, increasing brand online operation services, and strengthening brand culture and product innovation. This paper will point out the excellent enterprises and brands in the face of difficulties in the face of excellent adaptability, as well as the brand internal management personnel excellent economic mind and wisdom.
\end{abstract}

Keywords: Pandemic; Economic wisdom; Innovation; Price raising; Online shops, Offline service

With the outbreak of COVID-19 at the end of 2019, the golden age of luxury goods has come to an end. Driven by the global economic prosperity and the relative affluence of Chinese consumers, the crisis has slowed the growth of luxury goods industry for a decade. In recent years, Chinese consumers have accounted for $35 \%$ of the world's luxury goods. Now, even the most optimistic forecasts suggest that luxury sales will fall by $25 \%$ to $45 \%$ in 2020 . At the best of times, when vaccines are available or the economic impact of a pandemic is less severe, people will resume shopping and travel and promote luxury sales. But in the worst case, vaccine development will take a longer time, or the economic recession will be more serious, so it will be difficult for enterprises to regain momentum, and people's ability and willingness to buy luxury goods will be affected. Because of such uncertainty, luxury brands have to make corresponding changes and policies to cope with the global disaster in order to survive. It is proved that luxury brands have gained benefits in the epidemic period and post epidemic era through new measures. This article analyzes the strategies of luxury brands to protect and develop their brands during the outbreak, and they reflect the economic wisdom of brands by raising prices, digitalization, and innovation to help brands continue to climb during the epidemic.

For the retail industry, selling products is their most direct source of income, and increasing commodity prices is the most direct way to increase their income. In order to cope with the loss of revenue caused by the epidemic, luxury brands like Louis Vuitton have raised their retail prices several times in 2020. Louis Vuitton raised prices in March and May 2020, and its best-selling product, Alma BB bag, rose from RMB 9,350 in April 2019 to RMB 10,400 in April 2020 and RMB 10,900 today. The data show that the price of Louis Vuitton has risen by more than 15\% since August 2019. More and more investors are buying luxury 
goods because they don't know when the next price hike will be. Louis Vuitton's growth during the epidemic is very amazing. Their fashion and leather goods grew by $12 \%$ in the third quarter 2020 , which is contrary to the financial analysts' prediction at the beginning of this year. In October, LVMH group's share price also soared by 7.3, the highest since January this year. Many experts believe that the main reason for these results is price raising strategy. However, the alleviation of the epidemic situation in China is also one of the reasons. China has stabilized the epidemic from June to July 2020, giving Chinese consumers the opportunity to consume and shop offline. Because of the long-term depressed desire for shopping and the repeatedly increased retail prices, China, which accounts for 35\% of the world's luxury goods consumption, has shown more crazy performance at the middle of the 2020, according to reports China saw double-digit sales growth in the second quarter, while duty-free stores in Hainan recorded a 167\% increase during the week-long National Day holiday. The surge in retail sales and higher prices make the luxury industry had such unexpected profits during the epidemic period. The luxury industry finds its way forward in the dark by simply raising prices.

For luxury brands, many of them have history of more than 100 years, and the traditional consumption and shopping mode seems to be one of the elements of these brands passed down from generation to generation. Walking in shopping malls full of boutiques and fitting luxury goods are also the understanding of luxury shopping mode in many people's minds, but in 2020, it seems that everything changed. Offline sales are no longer loved by luxury brands. New Internet online sales create more value for old luxury brands. In 2020, online sales of personal luxury goods account for $8 \%$ of the global luxury market of 254 billion euro. That's about 20 billion euros, a fivefold increase over 2009, and online luxury sales are expected to more than triple by 2025, to about 74 billion euros. Nearly a fifth of personal luxury sales will be online. In addition, Amazon, the world's largest online retailer, also announced the launch of luxury retail in September 2020, which further accelerated the process of electronic luxury goods. Therefore, the retail industry of luxury goods has not been greatly affected by the suspension of offline services. They have more retail channels than before. They even move the whole offline retail stores to the online world. They sell the same products at the same price as offline stores, and the returns are the same as those of offline sales as well and because online sales don't have to pay for the maintenance costs of stores, they can even get more returns. The digitalization does not only affected the retailing markets, but also the traditional fashion shows. Paris Fashion Week is the largest luxury feast in the world, and it has lasted for a hundred years. Even during the Second World War, Paris fashion week also went on as usual. However, in 2020's special epidemic environment, the offline fashion week was cancelled, and replaced by online shows. In July, FHCM held the first virtual fashion week in Paris. During the three-day digital event, the certified fashion house showed videos and supplemental content, which were broadcast live according to the preset display schedule, imitated the form of physical fashion week and followed the conventional fashion design, such as Christine Dior, Chanel, Valentino, Maison Margiela and they displayed their new products in the form of full electronics. Fashion editors and buyers all over the world can witness this feast of fashion through computers, and the purchase of fashion items is also in the form of Internet. FHCM announced that the spring 2021 men's wear collection will switch to pure video format, similar to the process of IRL men's fashion week, the digital fashion week will be organized in time periods, allowing continuous flow on a central platform. "Numbers are clearly part of the fashion of the future, and we will use it as an opportunity for innovation to complement tradition," said Ralph Toledano, FHCM president. "The electronic Internet has saved the luxury brands. By using the latest Internet technology, they let the business go on as usual. The epidemic can end the offline world, but it can't destroy the fantastic ideas of human beings on the Internet.

For the luxury brand itself, their brand value is huge, their own brand culture and innovation is loved by people all over the world, for the operation of the brand culture and create more excellent products can help the brand during the outbreak to make a profit. Louis Vuitton is still a very good example, they are 
very good for the operation of the brand 2020, in 2018 LV enrolled street designer Virgil Abloh into the brand, and let him serve as the brand's creative director of men's wear, he brought the young hip-hop street culture into this old fashion house, and thus attracted a large number of young luxury consumers, his appearance made LV's sale increasing by $20 \%$, firmly established itself as a pioneer in luxury youth, since then LV has started working with companies around the world, especially in this special 2020, Louis Vuitton will be the brand's operation to the extreme, earlier 2020 Louis Vuitton and the world's hottest eSports game LOL reached a partnership, launched a number of co-products, including bags, clothing, and will use LV's bags as a container for the championship trophy at this year's LOL World Finals. This is the first-time people have seen an old luxury brand on the eSports stage, and the partnership has taken LV to a whole new level, with many gamers spending more than $\$ 2,000$ on a hoodie with game characters printed on it, and LV becoming popular among gamers. In November 2020 LV launched a series of basketball and NBA-related bags and apparel products that will include leather bags with basketball patterns and NBA logos, etc., and this year's NBA championship trophy will also use LV's suitcase as a container, and NBA players will be asked to wear some of the co-ed clothing, a series of collaborations that Louis Vuitton promotes his brand. They brought luxury to the attention of more and more people during the outbreak, they may be gamers, athletes, but they can all understand and use LV products, luxury goods are no longer a commodity it may be a cultural imprint, which indirectly help brands live during the outbreak more attention and sales. Bottega Veneta, who innovated on the product, recruited young designer Daniel Lee late last year, the new LVMH award winner helped BV to launch the hot single for three quarters in a row, and his high-heeled boots allowed trend-loving boys and girls to run through several websites, only to find a pair of boots that suited them, and no one looked up to the brand until Lee came to BV, and the clothing sales were only $15 \%$ of the total for BV in 2019. It was a dismal one for an established luxury brand, but Lee's arrival changed all that, with sales soaring 6.9 percent and making the rickety brand the most popular luxury brand of the year in 2020, with fashion critics rating Bottega Veneta as a giant. The innovation of luxury brands has saved them, and they have taken their performance to a whole new level by working with the world's major companies to innovate their own products, which is not easy for an epidemicravaged market.

COVID-19 has disrupted the world, but the vibrant and creative luxury industry is not willing to be a loser of the epidemic, attracting large numbers of investors through simple price increases, and because the epidemic has eased in parts of the world, they have also enjoyed the benefits of rising prices and retail growth, luxury brands catering to the Internet industry to help them make up for losses in the retail industry, and even bring the entire fashion industry to a whole new era, Finally returned to the essence of

luxury brands, they through continuous innovation and cooperation to enhance the value of the brand, so that more and more people contact and understand luxury brands, the brand itself for product innovation has also impressed consumers and fashion industry professionals, the entire luxury industry will break out in the post-epidemic era more powerful force.

\section{References:}

Daniel Lee: the man behind Bottega Veneta's new buzz, Ellison, Jo, (November 22, 2019), Retrieved from https://www.ft.com/content/98bbeed2-c80f-4231-995f-4596d7e8c289

Digital Fashion Weeks and Virtual Shows: A Rundown of Fashion's New Rhythm, BROWCHUK, ELISEÉ, (June 29, 2020), Retrieved from https://www.vogue.com/article/digital-fashion-weeks-2020

How Daniel Lee became fashion's new boy wonder, De Klerkdec, Amy, (December 3, 2019), Retrieved from https://www.harpersbazaar.com/uk/fashion/fashion-news/a30107331/daniel-lee-bottegavenetal 
Luxury in the age of digital Darwinism, Achille, Antonio, Marchessou, Sophie, and Remy, Nathalie, (February 1, 2018), Retrieved from https://www.mckinsey.com/industries/retail/our-insights/luxuryin-the-age-of-digital-darwinism

Farfetch Is Perfectly Positioned for Luxury Market's Digital Post-Coronavirus Future, Danziger, Pamela, (May 16, 2020), Retrieved from https://www.forbes.com/sites/pamdanziger/2020/05/16/farfetch-isperfectly-positioned-for-luxury-markets-digital-post-coronavirus-future/?sh=295c662e7834

Luxury Institute 'State of the Luxury Industry' Survey Shows Strength Across Luxury Categories as Affluent Consumers Worldwide Benefit From Positive Economic Trends, Luxury, Institute, (January 2, 2020), Retrieved from https://www.globenewswire.com/newsrelease/2020/01/21/1972941/0/en/Luxury-Institute-State-of-the-Luxury-Industry-Survey-ShowsStrength-Across-Luxury-Categories-as-Affluent-Consumers-Worldwide-Benefit-From-PositiveEconomic-Trends.html

Luxury Industry Statistics and Insights in 2020, Industry, Profiles, (June 16, 2020), Retrieved from https://blog.clear.sale/luxury-industry-statistics-and-insights-in-2020 